\title{
Temporal and Spatial Distribution of Leishmania mexicana Infections in a Population of Neotoma micropus
}

\author{
Russell W Raymond, Chad P McHugh*/+, Loren R Witt, Sara F Kerr
}

Biology Department, University of the Incarnate Word, San Antonio, TX, USA *US Air Force Institute for Environment, Safety and Occupational Health Risk Analysis, 2513 Kennedy Circle, Brooks AFB, TX 78235, USA

A 19-month mark-release-recapture study of Neotoma micropus with sequential screening for Leishmania mexicana was conducted in Bexar County, Texas, USA. The overall prevalence rate was $14.7 \%$ and the seasonal prevalence rates ranged from 3.8 to $26.7 \%$. Nine incident cases were detected, giving an incidence rate of 15.5/100 rats/year. Follow-up of 101 individuals captured two or more times ranged from 14 to 462 days. Persistence of L. mexicana infections averaged 190 days and ranged from 104 to 379 days. Data on dispersal, density, dispersion, and weight are presented, and the role of $\mathrm{N}$. micropus as a reservoir host for $\mathrm{L}$. mexicana is discussed.

Key words: Leishmania mexicana - Neotoma micropus - prevalence - mark-release-recapture - transmission - ecology - Texas

Enzootic and zoonotic transmission of Leishmania mexicana Biagi, 1953 occurs in the Southwestern United States. Woodrats, Neotoma micropus Baird, 1855 in Texas and Neotoma albigula Hartley, 1894 in Arizona, are considered reservoir hosts because they were associated with Lutzomyia anthophora (Addis, 1945) and Lutzomyia diabolica (Hall, 1936), putative sand fly vectors (McHugh et al. 1993, McHugh 1999), and the prevalence of Leishmania infection in woodrat populations often exceeded 20\% (Kerr et al. 1995, Kerr et al. 1999). In Texas, the range of $N$. micropus coincided with that of human cases, and they were common near case residences (McHugh et al. 1990, 1996). Kerr et al. (1995) provided evidence that the fall was the season of transmission and determined that Leishmania was focal, with positive woodrats found at only four of 16 localities studied in Texas. Because of the extensive nature of their study, however, sampling efforts at each site were limited and temporally intermittent. Johnson (1952), Box (1959), Raun (1966) and Conditt and Ribble (1997) documented various aspects of the population ecology of $N$. micropus, including parasites and nest associates, of woodrats in south Texas, but none screened for infections with L. mexicana. Merkelz and Kerr (2002) investigated a population of woodrats in Texas for 20 months, screening all captures for Leishmania each season. While no infected woodrat was detected, longevity, natality, sex ratio, dispersion and movements of woodrats were documented. We conducted an intensive, long-term study of $N$. micropus at a single focus to determine seasonal variations in prevalence and spatial distribution of Leishmania-positive rodents, identify incident infections, and determine the persistence of infections in individu-

This work received financial support from US National Institutes of Health grant GM55337.

${ }^{+}$Corresponding author. Fax: +210-536-6841. E-mail: chad.mchugh@brooks.af.mil

Received 14 May 2002

Accepted 6 November 2002 als. Additionally, we measured characteristics such as survivorship and dispersal which may help explain the temporal and spatial distribution of infections. Results of concurrent sampling of sand flies at that focus were reported previously (McHugh et al. 2001).

\section{MATERIALS AND METHODS}

Study site - Collections were conducted from August 1998 through February 2000 on an annex of Lackland Air Force Base, located in western Bexar County, Texas, USA. The vegetation was south Texas brush characterized by mesquite (Prosopis glandulosa Torrey), Texas persimmon (Diospyros texana Sheele), huisache [Acacia farnesiana (L.)], agarito (Berberis trifoliolata Moricand) and scattered patches of pricklypear cactus (Opuntia sp.). The soil in this area is primarily Houston Black gravelly clay (USDA 1962). Historically, the climate at the site is generally sub-tropical with hot, humid summers and mild winters. Precipitation is bimodal with peaks in May and September and an annual total of $713 \mathrm{~mm}$ (National Climatic Data Center, Asheville, NC). Weather data were collected at Kelly AFB, TX, approximately $9.5 \mathrm{~km}$ to the east of the Lackland annex.

Trapping took place at three areas of the annex. Area A was approximately 4.8 ha, area B was approximately 0.8 ha, and area $\mathrm{C}$ was approximately 0.6 ha.

Trap release methods - Rodents were collected using 12.5 x 12.5 x $38 \mathrm{~cm}$ live traps (HB Sherman Traps Inc., Tallahassee, FL). In August of 1998, collections were made at seven nests in area A. By winter of 1998-1999 a total of 99 nests - 90 in area A, 6 in area B and 3 in area C-were routinely sampled each season. Locations of nest sites were determined using a Trimble Pro XRS receiver and TSC1 asset surveyor (Trimble Navigation Ltd, Sunnyvale, CA). Real-time differential correction was obtained using signals from the Coast Guard Beacon in Corpus Christi, $\mathrm{TX}$, resulting in sub-meter accuracy. The position information then was used to create site maps using the GIS software programs Pathfinder Office 2.11 (Trimble Navigation Ltd) and ArcView 3.1 (Environmental Research Institute, Inc., Redlands, CA). 
Two traps per nest were set in the evening and checked early the next morning, with as many as three attempts made to collect rodents at each nest during each season. When overnight temperatures were forecasted to be near freezing, polyester fiber was placed in the traps to provide insulation from the cold. Trapping was suspended when overnight temperatures were forecasted to be below freezing.

Woodrats were transferred from the traps into a cotton stockinette and weighed using a precision spring scale (Avinet Inc., Dryden, NY). Age of individuals was estimated by weight, with males weighing less than $170 \mathrm{~g}$ and females weighing less than $200 \mathrm{~g}$ classed as juveniles (Wiley 1972). Woodrats then were transferred into a wire mesh cone for ease of handling. On first capture, woodrats were marked with a glass-sealed microchip transponder (BioMedic Data Systems Inc., Seaford, DE) implanted just below the skin at the base of the neck (Rao \& Edmondson 1990, Ball et al. 1991). A tissue sample was collected from each ear of the animal using a sterile, disposable, $2 \mathrm{~mm}$ biopsy punch (Sklar Instruments, West Chester, PA). The sex of the woodrats was determined and they were released at the site of capture.

Laboratory procedures - Tissue biopsies were returned to the laboratory and processed using the methods described by Kerr et al. (1999). From August 1998 through January 1999, half of the ear tissue from all 112 captured woodrats was placed in culture. From February 1999 through February 2000, only ear tissue from firstcapture woodrats with obvious lesions - swellings, bumps, alopecia, or erosion of the pinna - or woodrats that had previously tested positive by polymerase chain reaction (PCR) for Leishmania was placed in culture. When cultured, the tissue collected from each ear was placed in a microcentrifuge tube, immersed in $70 \%$ isopropyl alcohol and shaken in a vortex mixer for $15 \mathrm{sec}$ to aid in the removal of contaminants. The tissue samples were cultured in medium M199 (Gibco-BRL, Gaithersburg, MD) supplemented with $20 \%(\mathrm{v} / \mathrm{v})$ heat-inactivated fetal bovine serum (Summit Biotechnology, Fort Collins, CO), 10 $\mathrm{mM}$ adenine (Sigma Chemical Co., St. Louis, MO), $0.25 \%$ (v/v) bovine hemin (Sigma), 50 mM HEPES buffer (Sigma), $50 \mathrm{IU} / \mathrm{ml}$ penicillin, and $50 \mu \mathrm{g} / \mathrm{ml}$ streptomycin at $\mathrm{pH}$ 7.4. The cultures were kept at $25^{\circ} \mathrm{C}$ and monitored at least twice weekly for the presence of promastigotes of Leishmania. Promastigotes were passed in supplemented M199 medium and sent to Dr RD Kreutzer for identification of parasites to species by isoenzyme analysis (Kreutzer \& Christensen 1980, Kreutzer et al. 1987).

Tissue biopsies from all ears were prepared and screened by PCR using the methods described by Rodgers et al. (1990) and Kerr et al. (1999). The samples were placed in $40 \mu$ of lysing buffer ( $10 \mathrm{mM}$ Tris/10 mM EDTA, $\mathrm{pH}$ 8.0) and incubated at $94^{\circ} \mathrm{C}$ for $30 \mathrm{~min}$. The master mix was prepared using final concentrations of $1 \mathrm{X}$ PCR reaction buffer (Boehringer-Mannheim, Germany), $0.2 \mathrm{mM}$ nucleotides (Boehringer-Mannheim), $1 \mu \mathrm{M}$ forward and reverse primers, 13A and 13B (Dr P Melby, UTHSC, San Antonio, TX), DNAse-free water (United States Biochemical, Cleveland, $\mathrm{OH}$ ), and $0.75 \mathrm{U} / 25 \mu \mathrm{l}$ Taq polymerase (Boehringer Mannheim). The samples were allowed to proceed through 30 cycles of amplification and then were analyzed on an agarose gel alongside a DNA ladder. Positive samples were identified by the presence of a band at the $120 \mathrm{bp}$ region of the gel.

Temporal and spatial distribution of infections - A prevalence rate for the entire study period was calculated as the number of individuals testing positive at any time during the study divided by the total number of individuals tested. Recaptured animals were included only once in the denominator and, if positive, once in the numerator. The seasonal prevalence of infection was calculated as the number of individuals that tested positive for Leishmania within each three-month season divided by the total individuals trapped during that season. Recaptured animals were included only once in each season they were trapped. Sex- and weight-specific prevalence rates also were calculated.

Incident cases were those individuals who tested PCRnegative at least once and then tested positive on a subsequent capture. Transmission was presumed to have taken place between the last negative and first positive test. The incidence rate was estimated by considering the number of susceptible rodents, the period over which they were susceptible (the total interval between first and last capture or the interval between first capture and first PCR-positive screening), and the number of incident cases. All rodents who were PCR-negative on first capture were assumed to be susceptible. Individuals who were PCRnegative, but captured only once, were considered lostto-follow-up and not included in the determination of the incidence rate.

Persistence of infection was defined as the number of months an individual remained positive by PCR. Survivorship of individual rodents was defined as the number of months between first and last capture. Dispersal was defined as the distance between successive captures of the same individual.

Statistical tests - A contingency chi-square $(\alpha=0.05)$ was calculated to test the hypotheses that there were no differences in prevalence rates between sexes. A chisquare $(\alpha=0.05)$ also was used to compare the proportion of males and females who dispersed during the study. A two way ANOVA $(\alpha=0.05)$ and Duncan's multiple range test were used to test for the effect of sex and infection status on length of follow-up and the distance the rodents dispersed during the study.

The density of nests was calculated by drawing a sixsided polygon enclosing the nests in area A and calculating the area enclosed using the ArcView software. This calculation was done twice, once using all nests in area $\mathrm{A}$, and once excluding the northmost nest which was separated from the rest by an open, grassy field that was uninhabited by woodrats. A nearest-neighbor spatial analysis (Sinclair 1985) was performed with, and without, the northmost nest to determine if woodrat nests were clustered, randomly distributed, or uniformly dispersed in the study area $(\alpha=0.05)$. The test was repeated using only those nests at which an infected rodent was collected. Nests at which more than one infected woodrat was collected were counted multiple times with a nearest neighbor distance of $0 \mathrm{~m}$. The seasonal density of rodents was 
calculated by dividing the number of individuals captured by 4.8 ha.

\section{RESULTS}

The entire study period and several months preceding it can be characterized as hotter and drier than normal. There was a short episode of record rainfall in October of 1998 , but much of this ran off as floodwater and did little to relieve the existing drought. If the excess precipitation during the month is discounted, the annual precipitation was about $50 \mathrm{~mm}$ below average. In much of south Texas, 1999 was exceptionally hot and dry, with temperatures at, or well above, historic means every month except July. Rainfall in the study area was $403 \mathrm{~mm}$, about $300 \mathrm{~mm}$ below average. January and February of 2000 continued hotter than average, but with normal rainfall.

During the 19 months of the study, a total of 1,309 trap nights captured 237 individuals a total of 454 times for an overall trap success rate of $34.7 \%$. One hundred twelve individuals were male, 125 were females (male:female ratio $1: 1.1)$. One hundred thirty-one individuals were captured only once; 106 individuals were recaptured one or more times for a recapture rate of $44.7 \%$.

Other rodent species were not commonly captured, and were limited to a very few hispid cotton rats (Sigmodon hispidus Say and Ord, 1825). Large mammals, such as white-tailed deer [Odocoileus virginianus (Zimmerman, 1780)], feral hogs (Sus scrofa L., 1780) and coyotes (Canis latrans Say, 1823), are known to occur on the annex, but rarely were in evidence.

Temporal and spatial distribution of infections - No infections were detected in the 16 woodrats collected in Area B or the 10 woodrats captured in Area C, and those individuals were not included in any additional analyses. Of the 211 woodrats collected in Area A, 31 (14.7\%) tested positive by PCR and/or culture at some time during the study. The prevalence in males $(20 / 110 ; 18.2 \%)$ and females $(11 / 101 ; 10.9 \%)$ were not significantly different $\left(\chi^{2}\right.$ $=2.19 ; \mathrm{P}>0.1)$. Seasonal prevalence rates ranged from $3.8 \%$ to $26.7 \%$ and were above $10 \%$ in the summer and fall of both years (Table I).

Three isolates (WHO designations MNEO/US/98/ Bexar20, MNEO/US/98/Bexar21, and MNEO/US/99/ Bexar22) were cultured and characterized by isoenzyme analysis. All three were determined to be L. mexicana. Cultures were deposited with cryobank at the Walter Reed Army Institute of Research.

In the summer of 1998, the first season of the study, limited sampling detected a single, positive rodent captured at the western edge of area A (Fig. 1). In the fall of 1998, additional nests were sampled and revealed a cluster of positives near the nest at which the initial positive was captured. Because all the positives in the fall were initial captures, all were considered prevalent cases. During the winter of 1998-99, trapping was conducted at all 90 nests in area A. The eight prevalent cases found that season formed a loose cluster in the area where positives had been collected previously. Thus far, no positives were captured in the southern one-third of the study area. In the spring of 1999 (Fig. 2), three of the four positive rodents were incident infections. One was captured at a nest $12 \mathrm{~m}$ from a nest at which a positive was collected the previous season; a second incident case was captured 31 $\mathrm{m}$ from the nearest previously-positive capture. The third incident case was the northmost positive captured to date. That nest was $60 \mathrm{~m}$ from a nest at which a positive woodrat was captured the previous season. As was the case the previous season, no positive animals were detected in the southern third of the study area. In the summer of 1999 (Fig. 2), one prevalent and one incident infection were detected near the southern edge of the area. An additional prevalent case was found at the northmost nest in the study area, and an incident infection was detected at the eastern edge of the area. Two positive rodents $-\mathrm{a}$ female who tested positive twice previously and a positive male who was captured only once - were collected at the same nest in early September. In the fall of 1999, positive rodents, including two incident infections, were scattered throughout the area. In the winter of 1999-2000, the last season of the study, only two positive rodents, both incident infections, were captured. The southmost individual was captured at a nest $12 \mathrm{~m}$ distant from an incident case the previous season.

Incident infections - Of the 31 positive individuals identified during the study, six males and three females represented incident cases (Fig. 3). Three incident cases were detected in the Spring of 1999, and two were detected in each of the succeeding three seasons. For three

TABLE I

Seasonal prevalence of Leishmania mexicana in Neotoma micropus and seasonal density in area A of Lackland annex, Bexar County, Texas, USA

\begin{tabular}{|c|c|c|c|c|}
\hline & Male & Female & Total & Seasonal density ${ }^{a}$ \\
\hline Season & No. pos/Total (\%) & No. pos/Total (\%) & No. pos/Total (\%) & Rodents/ha \\
\hline Summer 1998 & $0 / 2(0)$ & $1 / 5(20)$ & $1 / 7(14.3)$ & $\mathrm{nc}$ \\
\hline Fall 1998 & $4 / 15(26.7)$ & $4 / 15(26.7)$ & $8 / 30(26.7)$ & $\mathrm{nc}$ \\
\hline Winter 1998-1999 & $4 / 52(7.7)$ & 4/41 (9.8) & 8/93 (8.6) & 19.4 \\
\hline Spring 1999 & $3 / 36(8.3)$ & $1 / 29(3.4)$ & $4 / 65(6.2)$ & 13.5 \\
\hline Summer 1999 & $6 / 48(12.5)$ & $2 / 22(9.1)$ & $8 / 70(11.4)$ & 14.6 \\
\hline Fall 1999 & $5 / 31(16.1)$ & $4 / 44(9.1)$ & $9 / 75(12)$ & 15.6 \\
\hline Winter 1999-2000 & $1 / 29(3.4)$ & $1 / 23(4.3)$ & $2 / 52(3.8)$ & 10.8 \\
\hline
\end{tabular}

$a$ : densities for the summer and fall of 1998 were not computed since the entire 4.8 ha area was not trapped. 
of the individuals, the interval between negative and positive screenings spanned more than one season, making it impossible to determine the presumed season of transmission. In two cases, transmission appeared to take place in the late winter of 1998-1999 or early spring of 1999. One infection was acquired in the late spring to mid summer of 1999, and three infections were acquired in the late fall of 1999 through mid-winter of 1999-2000. An incidence rate of 15.5/100/year was calculated based on an initial, susceptible population of 91 individuals among whom there were nine conversions to PCR-positive during a total of 58 rat-years of follow-up.

Follow-up - One hundred-one individuals in area A were captured two or more times. Follow-up for females infected at any time ranged from 278 to 462 days which was significantly longer than uninfected animals, but not
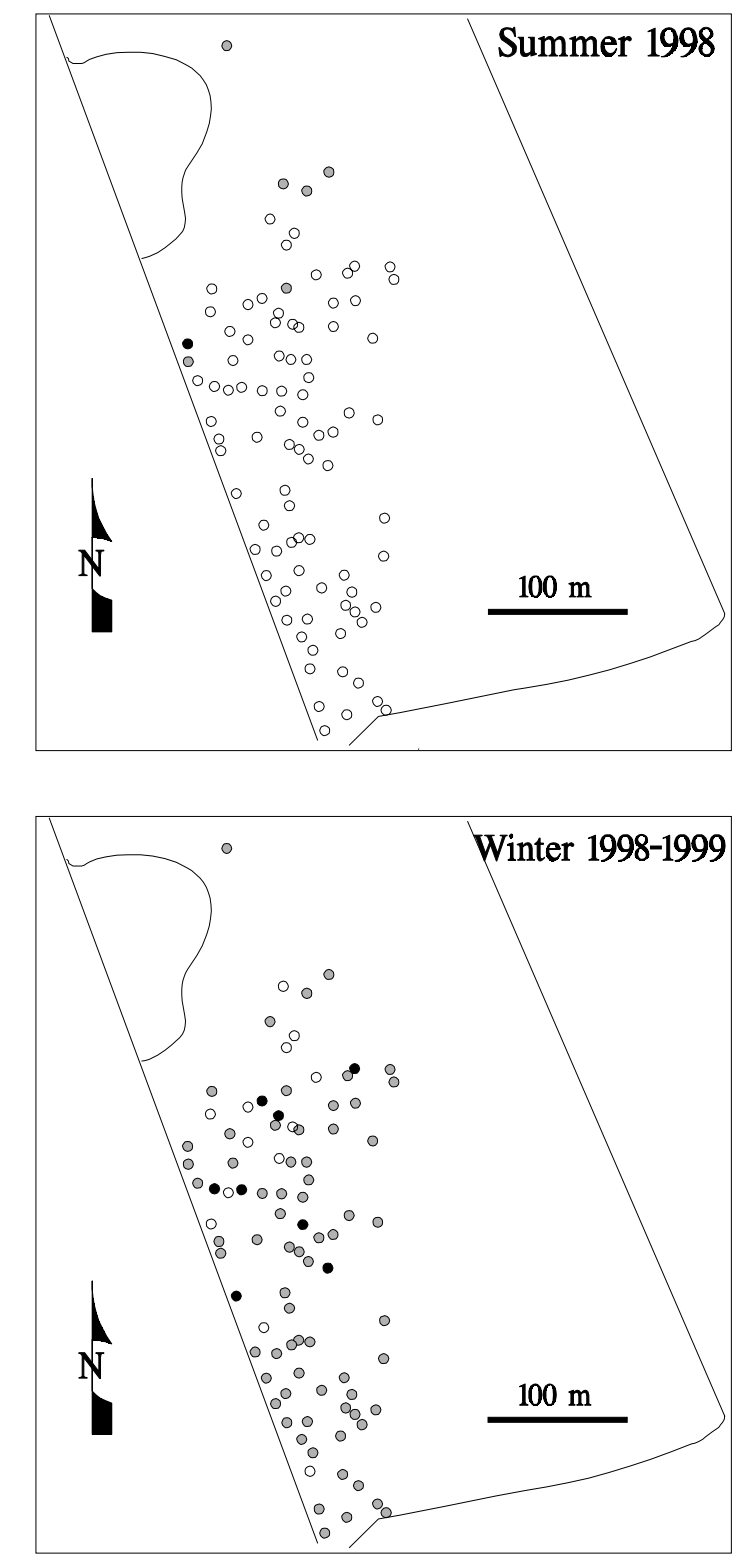

Fig. 1: results of screening Neotoma micropus in Bexar County, Texas USA, from the summer of 1998 through the winter of $1998-1999$. $\bigcirc$ : not trapped/no rodent captured; $\bigcirc$ : negative for infection; different from infected males at 99 to 470 days (Table II). Follow-up intervals for uninfected females ranged from 14 to 463 days and from 14 to 516 days for uninfected males. Forty-two individuals were monitored from their 1999-2000. Of the nine females that were juveniles on first capture, only two were recaptured.

Persistence of infections - Of the 101 animals captured two or more times, three adult males and two adult females had persistent infections detected on two or more consecutive screenings. The time between first and last positive screenings ranged from 104 to 379 days (mean 190.6, s.d. 111.0 ). The longest-running infection was an adult female who tested positive on first capture in early December of 1998 and continued positive until mid-December 1999, after which she was lost to follow up. Two

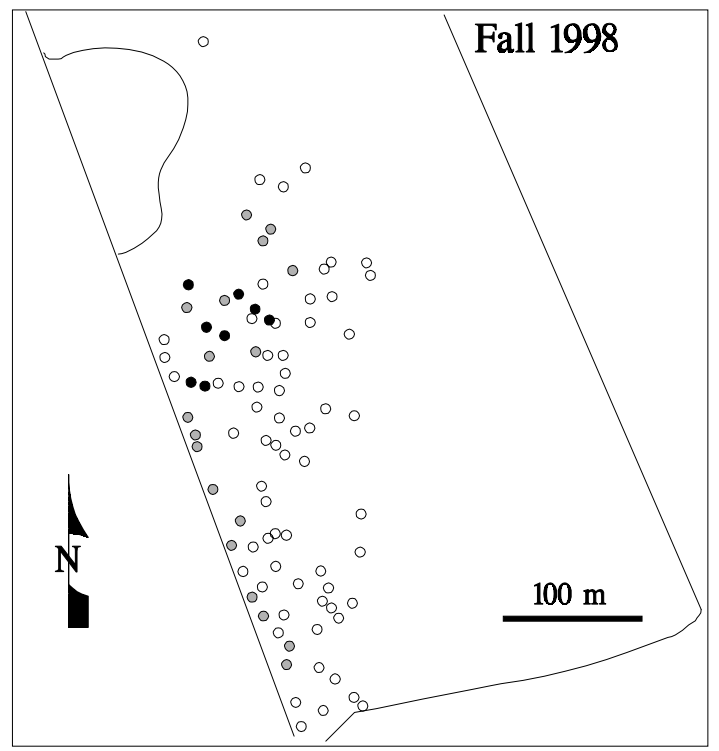
initial capture until the end of the study in the winter of : negative for infection; $\bullet$ : one prevalent infection 
males and one female were incident cases that persisted for 104, 177 and 180 days, respectively, when the animals were lost to follow up. Seven males and three females who were PCR positive on at least one occasion were negative on the subsequent screening.
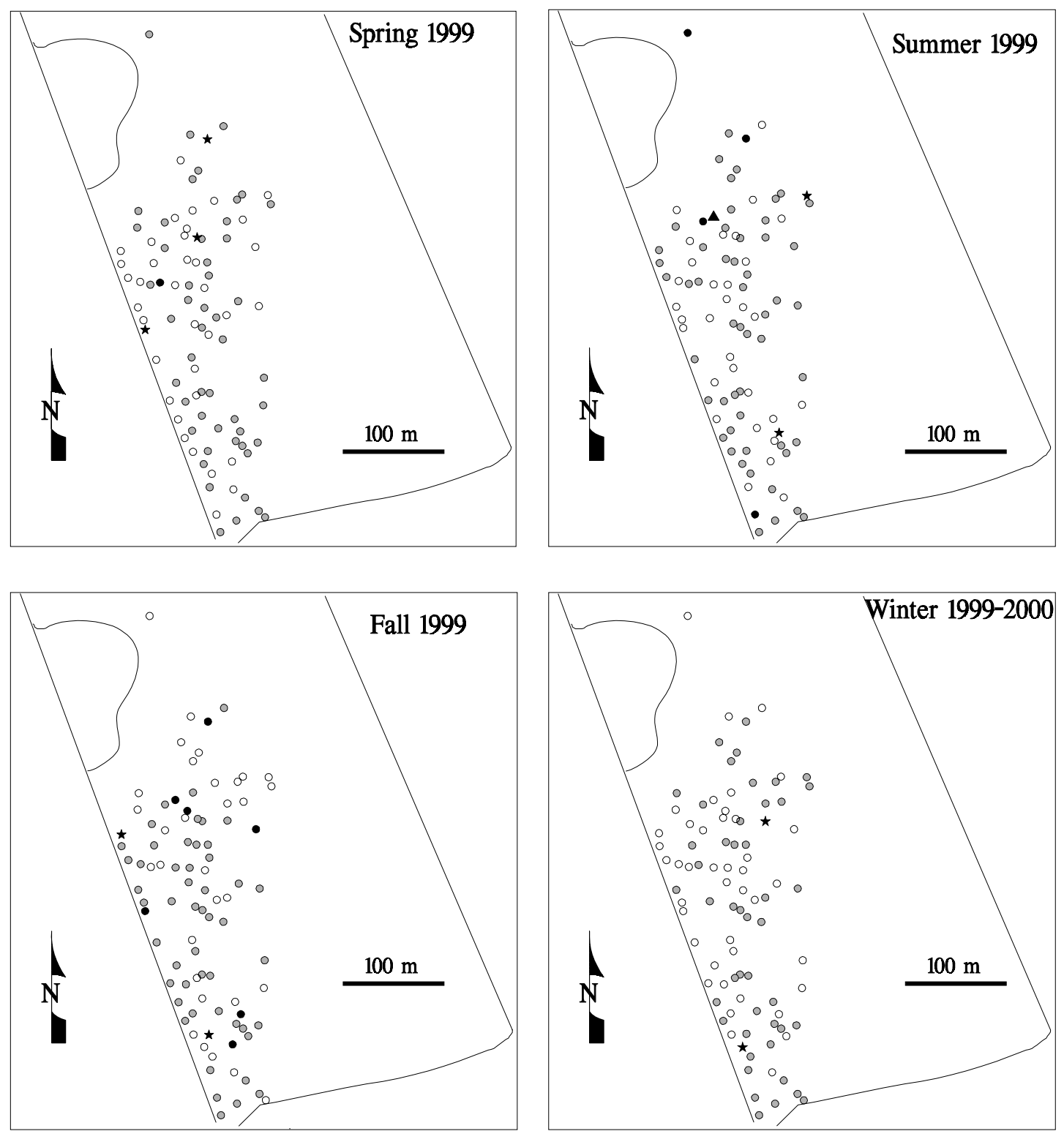

Fig. 2: results of screening Neotoma micropus in Bexar County, Texas USA, from the spring of 1999 through the winter of $1999-2000$. $\bigcirc$ : not trapped/no rodent captured; $\bigcirc$ : negative for infection; $\boldsymbol{O}$ : one prevalent infection; $\boldsymbol{\Delta}$ : two prevalent infections; $\star$ : incident infection

TABLE II

Follow-up of Neotoma micropus captured in area A of Lackland annex, Bexar County, Texas, USA

\begin{tabular}{llrcrc}
\hline Sex & & \multicolumn{2}{c}{ Mean Follow-up } \\
(Days) & S.D. & Group $a$ \\
\hline Female & Infection status & $\mathrm{N}$ & 339.7 & 71.6 & $\mathrm{a}$ \\
Male & Positive & 6 & 269.0 & 129.2 & $\mathrm{ab}$ \\
Female & Positive & 12 & 232.9 & 113.5 & $\mathrm{~b}$ \\
Male & Negative & 38 & 231.0 & 126.3 & $\mathrm{~b}$ \\
\hline
\end{tabular}

$a$ : groups with the same letter are not significantly different. 


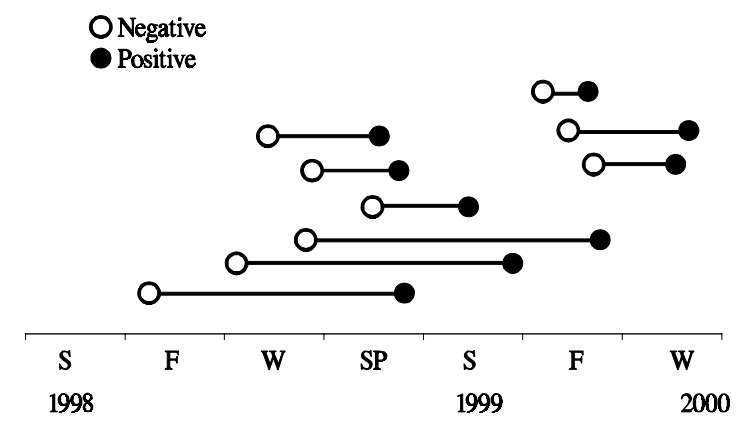

Fig. 3: timing of incident infections of Leishmania mexicana in a population of Neotoma micropus in Bexar County, Texas, USA.

There was no significant effect of sex or infection status on the total distance moved (Table III). The most moves were recorded by a male who moved four times among three different nests and another male who moved four times between two nests. The longest distance between any two captures as well as the longest total distance for all captures was a Leishmania-positive male captured in October 1998 and again in January of 2000 at a nest $73.2 \mathrm{~m}$ distant.

Of the 18 animals infected at any time during the study and captured at least twice, only four - three males and one female - were recaptured at different nests. In each of these cases, the individuals tested positive on only one of their captures. All individuals who tested positive multiple times were faithful to one nest.
Weight - Woodrats captured in area A weighed from 105 to $490 \mathrm{~g}$. A total of nine juvenile females $(<200 \mathrm{~g})$ was captured in the months of January (one), May (two), June (three), October (one), and December (two). No juvenile females were Leishmania-positive; the smallest positive female weighed $270 \mathrm{~g}$ (Table IV). No juvenile males ( $<170$ g) were captured. The smallest male weighed $190 \mathrm{~g}$; the smallest Leishmania-positive male weighed $310 \mathrm{~g}$. Infections were identified in all weight classes above $250 \mathrm{~g}$.

Density and dispersion - Including the northmost nest, area A was comprised of 4.8 ha for a density of 18.8 nests/ ha. Excluding the northmost nest and adjacent area devoid of woodrat nests gave a density of 22.8 nests/ha. For all nests, the observed mean distance (OMD) to the nearest neighbor was $13.1 \mathrm{~m}$ which was not significantly different from $12.2 \mathrm{~m}$, the expected mean distance (EMD) if the nests were distributed randomly. Deleting the northmost nest from the calculation gave an OMD of 12.1 $\mathrm{m}$ which was not significantly from the EMD of $11.0 \mathrm{~m}$ for randomly-distributed nests.

The seasonal density of woodrats in area A for seasons in which the area was thoroughly trapped varied from 18.8 rats/ha in the winter of 1998-1999 to 11 rats/ha in the winter of 1999-2000 (Table I).

Twenty-two of the 90 nests each yielded a single positive individual. At each of three sites, two positive $N$. micropus were captured, and at one nest three infected woodrats were collected. At the remaining 64 nests, only negative woodrats were captured. A nearest neighbor analysis of the nests at which positive rodents were captured gave an OMD of $20.2 \mathrm{~m}$ for the entire area and 19.8

TABLE III

Total distances traveled by Neotoma micropus captured in area A of Lackland annex, Bexar County, Texas, USA

\begin{tabular}{llrrrr}
\hline Sex & Infection status & N & $\begin{array}{c}\text { Mean } \\
(\mathrm{m})\end{array}$ & S.D. & Group \\
\hline Male & Positive & 12 & 11.1 & 25.4 & $\mathrm{a}$ \\
Female & Negative & 38 & 9.2 & 13.6 & $\mathrm{a}$ \\
Male & Negative & 45 & 7.2 & 14.2 & $\mathrm{a}$ \\
Female & Positive & 6 & 6.0 & 14.7 & $\mathrm{a}$
\end{tabular}

$a$ : groups with the same letter are not significantly different.

TABLE IV

Weight-specific prevalence of Leishmania mexicana in Neotoma micropus captured in area A of Lackland annex, Bexar County, Texas, USA

\begin{tabular}{|c|c|c|c|}
\hline & Male $^{a}$ & Female $^{a}$ & Total \\
\hline Weight (g) & No. pos/Total (\%) & No. pos/Total (\%) & No. pos/Total (\%) \\
\hline Juvenile $^{b}$ & $\mathrm{nc}^{c}$ & $0 / 9(0)$ & $0 / 9(0)$ \\
\hline > Juvenile-249 & $0 / 9(0)$ & $0 / 12(0)$ & $0 / 21(0)$ \\
\hline $250-299$ & $0 / 16(0)$ & $2 / 27(7.4)$ & $2 / 43(4.7)$ \\
\hline $300-349$ & $3 / 31(9.7)$ & $4 / 53(7.5)$ & $7 / 84(8.3)$ \\
\hline $350-399$ & $13 / 77$ (16.9) & $8 / 65(12.3)$ & $21 / 142(14.8)$ \\
\hline $400-449$ & $5 / 75(6.7)$ & $3 / 15(20)$ & $8 / 90(8.9)$ \\
\hline $450-499$ & $2 / 15(13.3)$ & $0 / 1(0)$ & $2 / 16(12.5)$ \\
\hline Total & $23 / 223(10.3)$ & $17 / 182(9.3)$ & 40/405 (9.9) \\
\hline
\end{tabular}

$\bar{a}$ : includes first captures and all recaptures for which screening was conducted; $b$ : females $<200 \mathrm{~g}$; males $<170 \mathrm{~g} ; c$ : none captured. 
when the northmost nest was excluded. Neither was significantly different from their respective EMD's of $21.7 \mathrm{~m}$ for all nests and $19.8 \mathrm{~m}$ excluding the northmost nest, indicating a random distribution for positive nests.

\section{DISCUSSION}

The overall trap success of $34.7 \%$ for areas A, B, and $\mathrm{C}$ in our study was slightly higher than the $28.3 \%$ reported by Conditt and Riddle (1997) and much higher than the $10.4 \%$ reported by Merkelz and Kerr (2002) who trapped at the La Copita research area near Alice, TX. The lower trap success at La Copita reflects the much lower density of woodrats, with a peak seasonal density of 1.5 woodrats/ ha (Merkelz \& Kerr 2002) compared to 19.4 woodrats/ha at Lackland annex in our study. In addition, a wide variety of rodent species entered traps at La Copita (SF Kerr unpublished observations) which interfered with the collection of N. micropus. Rodents other than N. micropus rarely entered traps at area A of Lackland annex.

A recapture rate of $44.7 \%$ for all areas in our study was much lower than the $72.2 \%$ recapture of Conditt and Ribble (1997), but their study covered fewer nests and they trapped more intensively over a shorter period of time resulting in a trapping effort per nest about 2.5 times that in our study. Additionally, they used radio collars to help track individuals. Merkelz and Kerr (2002) trapped at an intensity about twice that in our study, but reported a recapture rate of only $20.6 \%$. The latter study was conducted in a much larger area in which nests were sparsely distributed. Rodents moved farther and more frequently than in our study, which probably contributed to the lower recapture rate.

A male:female sex ratio of 1:1.1 for areas A, B, and C combined in our study was very similar to ratios found by Merkelz and Kerr (2002) and Thies and Caire (1991), who found ratios of 1:1.1 and 1:1, respectively. Conditt and Riddle (1997) reported a higher proportion of females (ratio 1:1.6), but their sample size $(\mathrm{n}=16)$ was small, making it more prone to measurement error.

Temporal and spatial distribution of infections - The overall prevalence rate of $14.7 \%$ was comparable to those determined by Kerr at al. (1995) who sampled several populations of N. micropus from 1989 through 1992 and reported rates of from 5.6 to $27 \%$ at four foci in southern Texas. However, since they used cell culture as the main diagnostic technique, these undoubtedly are underestimates. Additionally, the small sample sizes ( $\mathrm{n}=6$ to 27) limited the reliability of the estimates. Kerr et al. (1999) reported a prevalence of 33\% ( $\mathrm{n}=18)$ of Leishmania infection in a population of N. albigula in southern Arizona.

Infections were first detected at the western edge of the study site and spread through the population during the 19 months of the study. In the first two seasons, the distribution of infections was an artifact of the limited sampling that was concentrated in that part of the study area. During the following two seasons, with sampling conducted at all 90 nests, infections were still limited to a relatively small area. Eventually infections, including incident cases, were detected at the periphery of the study area. Although the infection appeared to spread through the population during the course of the study, most posi- tive rodents seemed to be somewhat clustered. Seventeen $(54.8 \%)$ of the 31 positives were captured within an approximately half-hectare section in the west-central portion of the area. All four nests that produced multiple, positive woodrats also were located within this area. The nearest neighbor analysis, however, determined that, over the entire period of the study, the distribution of infected wood rats did not depart from random.

If, in fact, we did observe the spread of infection through a naïve population, a number of mechanisms may have contributed to this spread. The movement of positive animals is an obvious mechanism, but may not fully explain the spread of infection, since animals with prevalent infections did not appear to disperse. That is, no Leishmania-positive animals collected at one nest moved and tested positive on a subsequent capture at a different nest. A male testing positive in October 1998 was negative when collected $73 \mathrm{~m}$ to the south in January of 2000 . A second infected male, positive on first capture, moved to two other nests where he tested negative. He moved a total of about $56 \mathrm{~m}$, but within a very circumscribed, triangular-shaped area. It is possible these two individuals introduced parasites and infected sand flies at new areas before clearing their infections and being recaptured, but our data will not allow us to test that hypothesis. An incident case, a female captured at three different nests over 343 days, was positive on her last capture. It is possible she became infected after her penultimate capture at one nest and introduced parasites to the area where she was collected the final time, but we cannot determine that.

Dispersal of infected sand flies is another possible mechanism of spread of woodrat infections in the area, but nothing is known about the dispersal capability of Lutzomyia spp. in North America. A third mechanism of spread is the movement of infected animals from outside the periphery of the study area into the area. Although there were some cases of prevalent infections found at the periphery of the area, several were incident cases, suggesting they were acquired in the area, rather than being introduced from outside.

Incident infections - The nine incident cases comprised $29 \%$ of all infections detected during the study. Of the incident cases for which a period of transmission could be estimated, most appeared to have acquired their infections during the cooler months of the year. This is in agreement with Kerr et al. (1995) who found a preponderance of incident rodent cases in the fall and with McHugh et al. (1996) who reported the time of onset for most human cases in Texas as cooler months of the year.

There are no data documenting the influence of a prior Leishmania infection on the susceptibility of $N$. micropus to reinfection, and we did not monitor the immune status of the rodents. The calculated incidence rate of 15.5/100/ year is based on the assumption that all PCR-negative animals were susceptible. If animals resistant to infection were present among the PCR-negative individuals, this would mean we overestimated the population-at-risk and that $15.5 / 100 /$ year is an underestimate of the true incidence rate. 
Follow-up - The average follow-up of 8.2 months for all females in our study is in reasonable agreement with Raun (1966) who reported following females an average of 7.6 months. Males in our study were followed an average of 8.0 months which was longer than the 5.6 months reported by Raun (1966). Merkelz and Kerr (2002) followed a total of 37 males and females an average of 5.9 months.

Infected animals were followed longer than uninfected ones. In the case of infected females, the difference was significant. This probably does not indicate a protective effect of Leishmania infection, but rather the fact that individuals followed longer had a greater opportunity to become infected at some time during their life. This possibility is supported by the fact that the average follow up for the nine incident cases was 323 (s.d. 103.2) days, much longer than the 231.9 (s.d. 119.9) days for individuals who never were positive.

Follow-up is an underestimate of the longevity of rodents in this population. Of the 101 individuals captured two or more times, 99 already were adults when first captured, and 42 individuals were still being followed when the study ended. For example, the longest-followed male already weighed $400 \mathrm{~g}$ on first capture and was at least 18 months old (Raun 1966). This individual was followed an additional 516 days to the last season of the study, for an estimated longevity of at least 35 months. Likewise, a female weighing $420 \mathrm{~g}$ when first captured was followed an additional 463 days when the study ended, giving her an estimated longevity of at least 33 months. Similarly, Raun (1966) suggested adding at least six months to his figures of survivorship post-marking to estimate minimum longevity. The maximum longevity observed by Raun (1966) was a female who lived an estimated 27 months, but he suggested that some individuals lived at least 36 months. Merkelz and Kerr (2002) also estimated maximum survival as 27 months for a female collected in their study.

Persistence of infections - This is the first report of persistence of infections in woodrats, either from laboratory or field studies. The mean time of persistence, 190.6 days, likely is an underestimate of unknown proportions. In all five cases in which the animals tested positive on two or more consecutive captures, the individuals either were prevalent cases that acquired an infection an unknown length of time before first capture or were incident cases that persisted until they were lost to follow up. In the case of the longest-running positive, the adult female was infected before her first capture and continued positive until lost to follow up over a year later.

One individual, a female positive on first and last capture, was not included in the persistence estimate because she tested negative by PCR on an intervening capture. Based on that negative test, she was assumed to have cleared her infection and been reinfected at a later date. If her negative test is considered a false negative, and her infection persistent for the entire period of follow-up, 462 days, her inclusion in the calculation would raise the average time of persistence in the population to 236 days.

Even though it is an underestimate, a mean persistence of almost 200 days is epidemiologically significant because it indicates that infections in rats would persist from one season of sand fly activity to the next. However, it remains to be determined if a level of parasitemia detectable by PCR would be high enough to be infectious to sand flies feeding on the rodents.

Dispersal - Raun (1966) defined four types of movement: dispersal of young; daily movements within home range; movements of short duration outside typical home range; and shifts of home range. The paucity of juvenile recaptures in our study limited our ability to measure dispersal of young. One female weighing $125 \mathrm{~g}$ at first capture weighed $230 \mathrm{~g}$ when recaptured at the same nest 91 days later. A second female, first captured as a juvenile and recaptured twice, did move to another nest, but only after achieving a weight of $300 \mathrm{~g}$. We found no difference in the propensity of adult males and females to move and no significant effect of sex or infection status on the distance moved. In our study, the mean total distance moved was quite limited and ranged from 6 to $11.1 \mathrm{~m}$ for adults cross-classified by sex and infection status (Table III). This contrasts with the findings of Raun (1966) who reported that mean daily movements for males $(14.1 \mathrm{~m})$ were significantly longer than those of females $(6.9 \mathrm{~m})$. Similarly, Merkelz and Kerr (2002) reported more adult males (69\%) moving and moving farther (62 $\mathrm{m}$ per move) than females $(24 \% ; 5 \mathrm{~m}$ per move). The maximum distance moved $(73.2 \mathrm{~m})$ by an individual in our study contrasts with that of Raun (1966) who reported a male moving 210.4 $\mathrm{m}$ and Merkelz and Kerr (2002) who determined a maximum distance of $205 \mathrm{~m}$. We did not document home ranges in our study.

The difference between our study and those of Raun (1966) and Merkelz and Kerr (2002) in the effect of sex on the frequency and distance moved may be explained by differences in the population densities and quality of the habitat. In the La Copita area studied by Merkelz and Kerr (2002), the nests were often widely separated and the population density was low, peaking at only 1.5 woodrats/ha. The density of Raun's (1966) woodrat population fluctuated markedly and ranged from 0 to 30 woodrats/ha, reaching low levels presumably due to adverse weather conditions that destroyed suitable habitat. Poor habitat which results in low population density and widely spaced nests may force animals, particularly males, to disperse farther in search of mates or nest sites.

Weight - Juveniles, defined in our study by the criterion of Wiley (1972) as males less than $170 \mathrm{~g}$ and females less than $200 \mathrm{~g}$, comprised only $4.3 \%$ of the total individuals collected. This contrasts with the report of Raun (1966) who, although he did not provide criteria for determining juvenile status, found juveniles comprised $17.5 \%$ percent of the population over the 30 months of his study, with monthly percentages of juveniles ranging from 4 to $29 \%$. Similarly, Thies and Caire (1991) found juveniles $(<170 \mathrm{~g})$ made up $15.7 \%$ of individuals collected. Merkelz and Kerr (2002), who classified all individuals under $180 \mathrm{~g}$ as juveniles, reported an overall percent of $23 \%$ juveniles, with no significant seasonal peaks.

The relatively small percentage of juveniles in our study could reflect the negative impact of drought. Although it was not quantified, evidence of rodents gnawing on the bark of persimmons became increasingly evi- 
dent as the study progressed, suggesting the rodents were stressed for food, or water, or both. This physiological stress could result in anestrus females, in failure of females to carry litters full term, or in poor survivorship of the young.

Density and dispersion - In our study with a density of 18.8 woodrat nests/ha, the nests were randomly distributed. Thies and Caire (1991) found a random distribution in a subplot with a density of $31.5 \mathrm{~N}$. micropus nests/ ha, but an aggregated distribution in a subplot with 6.25 nests/ha. They argued that these different distributions reflected the quality of the habitat. In the high-density subplot there was abundant cactus and there was reduced competition, while in the low-density plot the habitat was marginal with little cactus, and animals were forced into what little was available. Other authors such as Johnson (1952), Box (1959), and Raun (1966) have documented a strong relationship between woodrat density and habitat, with higher numbers consistently found in areas of pricklypear and overhead cover. Our study site had only limited clumps of pricklypear, but was covered by an extensive area of thick brush and many downed trees that served as nest sites.

The peak seasonal density of 19.4 woodrats/ha in our area A was near the middle of the range of 5.5-50 woodrats/ ha in studies summarized by Merkelz and Kerr (2002). However, they noted that these values were greatly influenced by whether investigators limited sample plots to pricklypear habitat favored by woodrats or also included more open areas. Merkelz and Kerr (2002) reported a density of only 1.5 woodrats/ha in an area where Leishmania was not detected. It is unclear if there is a minimum density below which Leishmania transmission cannot be maintained, but, in populations of woodrats with the same initial prevalence of infection, a denser population would have more susceptible rodents in closer proximity to infected animals. This could increase the possibility that a sand fly feeding on an infected host would encounter a susceptible animal on a subsequent feeding.

Neotoma micropus as a reservoir host - We relied on PCR using primers $13 \mathrm{~A}$ and $13 \mathrm{~B}$ as the primary diagnostic technique. Rogers et al. (1990) documented that these primers are Leishmania-specific and do not amplify kDNA of Trypanosoma cruzi Chagas, 1909, a closely-related trypanosomatid that infects woodrats in Texas (Packchanian 1942), and our negative controls were consistently negative. Thus we believe the number of false positives in our study probably was negligible. Rogers et al. (1990) also demonstrated that PCR was extremely sensitive and could detect as few as 1 culture-derived parasite, but the ability of PCR to detect L. mexicana in tissues of $N$. micropus is unknown. The possibility exists that some infections were below the detection limit of PCR, or, if infections were localized, they may not have been sampled using the $2 \mathrm{~mm}$ biopsy punch. If there were false negatives, one or more of our estimates for prevalence, incidence, or persistence would be conservative. As noted above, our reliance on PCR results as an indicator of susceptibility status also may have resulted in a conservative estimate for the incidence rate.

The World Health Organization (WHO 1990) defined criteria that a vertebrate must fulfill to be considered a reservoir host of Leishmania. These included factors such as the abundance of hosts, the longevity of the host, the persistence and impact of infections, and the intensity of host-vector contact. No specific numbers were given for these traits, except for the prevalence of infection that was defined as, "considerable, in certain situations exceeding 20\%".

While the overall prevalence rate of $14.7 \%$ in our study was lower, it was clear that under the combination of abundance, density, longevity, prevalence, and persistence of infection we documented, as well as the sand fly abundance reported previously (McHugh et al. 2001), that the presence and transmission of L. mexicana in our population of $N$. micropus was maintained. Additionally, this occurred in the almost complete absence of any other rodents that could serve as reservoir hosts. These observations reinforce previous suggestions by $\mathrm{McHugh}$ et al (1990), Kerr et al. (1995), and McHugh et al. (1996) that $N$. micropus is the reservoir host for L. mexicana in Texas.

\section{ACKNOWLEDGEMENTS}

To Lackland annex, Texas for access to the study area; Dr RD Kreutzer and the Walter Reed Army Institute of Research for isoenzyme analysis; Dr PC Melby for consultation on the PCR; and Brian Ostrander, Neil McCrary, and Valerie Garza for their assistance with field and laboratory work.

\section{REFERENCES}

Ball D, Argentieri G, Krause R, Lipinski M, Robison R, Stoll $\mathrm{R}$, Visscher G 1991. Evaluation of a microchip implant system used for animal identification in rats. Lab Animal Sci 41: 185-186.

Box TW 1959. Density of plains wood rat dens on four plant communities in south Texas. Ecology 40: 715-716.

Conditt SA, Ribble DO 1997. Social organization of Neotoma micropus, the southern plains woodrat. Am Mid Nat 137: 290-297.

Johnson CW 1952. The Ecological Life History of the Packrat, Neotoma micropus, in the Brushlands of Southwest Texas, MA Thesis, Univ Texas, Austin.

Kerr SF, McHugh CP, Dronen Jr NO 1995. Leishmaniasis in Texas: prevalence and seasonal transmission of Leishmania mexicana in Neotoma micropus. Am J Trop Med Hyg 53: 73-77.

Kerr SF, McHugh CP, Merkelz R 1999. Short report: a focus of Leishmania mexicana near Tucson, Arizona. Am J Trop Med Hyg 61: 378-379.

Kreutzer RD, Christensen HA 1980. Characterization of Leishmania spp. by isozyme electrophoresis. Am J Trop Med Hyg 29: 199-208.

Kreutzer RD, Souraty N, Semko ME 1987. Biochemical identities and differences among Leishmania species and subspecies. Am J Trop Med Hyg 36: 22-32.

Merkelz RM, Kerr SF 2002. Demographics, den use, movements, and absence of Leishmania mexicana in southern plains woodrats (Neotoma micropus). Southwest Nat 47: 70-77.

McHugh CP 1999. Notes on the sand flies (Diptera: Psychodidae) of southern Arizona. Entomol News 110: 297-301.

McHugh CP, Grogl M, Kerr SF 1990. Isolation of Leishmania mexicana from Neotoma micropus collected in Texas. $J$ Parasitol 76: 741-742.

McHugh CP, Grogl M, Kreutzer RD 1993. Isolation of Leishmania mexicana (Kinetoplastida: Trypanosomatidae) from 
Lutzoymia anthophora (Diptera: Psychodidae) collected in Texas. J Med Entomol 30: 631-633.

McHugh CP, Melby PC, LaFon SG 1996. Leishmaniasis in Texas: epidemiology and clinical aspects of human cases. Am J Trop Med Hyg 55: 547-555.

McHugh CP, Ostrander BF, Raymond RW, Kerr SF 2001. Population dynamics of sand flies (Diptera: Psychodidae) at two foci of leishmaniasis in Texas. J Med Entomol 38: 268-277.

Packchanian A 1942. Reservoir hosts of Chagas' disease in the state of Texas. Natural infection of nine-banded armadillo (Dasypus novemcinctus texanus), house mouse (Mus musculus), opossum (Didelphis virginiana), and wood rats (Neotoma micropus micropus), with Trypanosoma cruzi in the state of Texas. Am J Trop Med 22: 623-631.

Rao GN, Edmondson J 1990. Tissue reaction to an implantable identification device in mice. Toxicol Pathol 18: 412-416.

Raun GG 1966. A population of woodrats (Neotoma micropus) in southern Texas. TX Mem Mus Bull 11: 1-62.

Rogers MR, Popper SJ, Wirth DF 1990. Amplification of kinetoplast DNA as a tool in the detection and diagnosis of Leishmania. Exp Parasitol 71: 267-275.

Sinclair DF 1985. On tests of spatial randomness using mean nearest neighbor distance. Ecology 66: 1084-1085.

Thies M, Caire W 1991. Nearest-neighbor analysis of the spatial distribution of houses of Neotoma micropus in southwestern Oklahoma. Southwest Nat 36: 233-237.

USDA-United States Department of Agriculture 1962. Soil Survey, Bexar Co., Texas.

Wiley RW 1972. Reproduction, Postnatal Development, and Growth of the Southern Plains Woodrat (Neotoma micropus) in Western Texas, PhD Thesis, Texas Tech Univ, Texas, $142 \mathrm{pp}$.

WHO-World Health Organization 1990. Control of the Leishmaniases, Tech Rep Ser No. 793, 158 pp. 